\title{
A relação técnico-atleta na ginástica artística feminina
}

http://dx.doi.org/10.11606/1807-5509201700030639

\author{
Maurício Santos OLIVEIRA* \\ Marco Antonio Coelho BORTOLETO*** \\ Myrian NUNOMURA****
}

* Centro de Educação

Física e Desportos,

Universidade Federal

do Espírito Santo,

Vitória, ES, Brasil.

** Faculdade de

Educação Física,

Universidade Estadual

de Campinas,

Campinas, SP, Brasil.

${ }^{* * *}$ Escola de

Educação Física e

Esporte de Ribeirão

Preto, Universidade

de São Paulo,

Ribeirão Preto, SP

Brasil.

\section{Resumo}

A qualidade das relações pessoais, circunscritas no contexto do Esporte, é determinante para a experiência esportiva e influencia os resultados conquistados por seus protagonistas: técnicos e atletas. 0 presente artigo visa apresentar e discutir o relacionamento técnico-atleta na Ginástica Artística Feminina por meio de um estudo de caso do tipo etnográfico. A pesquisa foi realizada em um ginásio de alto rendimento com ginastas de nível internacional. Observamos que, nessa microcultura, técnicos e atletas estão subordinados às idiossincrasias culturais mediadas por valores e principios peculiares que influenciam,

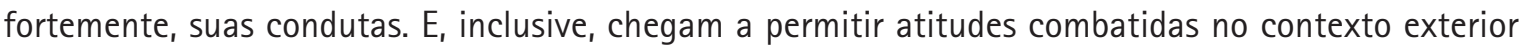
ao do ginásio de treinamento. As ginastas e os técnicos têm um acordo tácito no qual as atletas são vistas como corpos performáticos que devem cumprir as diretrizes dos técnicos sem questionamentos. Atos coercitivos, falta de diálogo, vigilância constante, subserviência e cobranças permeiam esse relacionamento escassamente debatido na literatura especializada.

PalaVRAS-Chave: Ginasta; Cultura-Treinamento; Formação Esportiva.

\section{Introdução}

O relacionamento entre técnico e atleta pode ser compreendido como um fator determinante para o sucesso esportivo. MARTENs ${ }^{1}$ L LYLE$^{2}$ destacam que os técnicos convivem e interagem por longos períodos com os seus atletas em uma dinâmica social na qual os valores, as aspiraçôes, as motivaçóes e outros aspectos próprios da dimensão humana na formação esportiva adquirem grande relevância, principalmente, quando se trata do desenvolvimento de jovens esportistas.

Desse modo, o vínculo estabelecido é caracterizado pela inter-relação, mútua e circunstancial, de aspectos afetivos, cognitivos e comportamentais que influenciam, sobremaneira, o desenvolvimento dos atletas ${ }^{3}$. BLоOM et al. ${ }^{4}$ ressaltam que, na maior parte dos casos, essa relaçáo ultrapassa o contexto esportivo e influencia o desenvolvimento global dos atletas ao promover o crescimento pessoal e social, opinião corroborada por Philippe e SEILER 5 .

PoczWardows Ki et al. ${ }^{6}$ mencionam três componentes principais presentes nesse relacionamento: o primeiro contempla o aspecto instrutivo que está associado às tarefas a serem executadas; o segundo aborda a questáo psicossocial que concerne aos aspectos afetivos e cognitivos; e, por último, o comportamental e espiritual que relacionase às crenças, tanto do atleta quanto do treinador, sobre a relação com o outro. De um modo geral, como afirmam RHIND e JowetT ${ }^{7}$, trata-se de um relacionamento cuja natureza é multidimensional e bidirecional, pois os sentimentos, os pensamentos e os comportamentos do técnico são afetados e, também, afetam os do atleta e vice-versa. 
A preocupação com a qualidade da relação técnico-atleta, principalmente, sob uma ótica holística complexa do treinamento esportivo, tornou-se mais evidente após a década de 1960, impulsionada por diversas mudanças sociais daquele período. De certa forma, segundo Sсотт $^{8}$ citado por LANNING" "junto com o movimento pelos direitos individuais, direito dos estudantes, e direito das mulheres houve um movimento paralelo pelos direitos dos atletas" (p. 262).

Até aquele período e, em alguns casos, até os dias atuais, o atleta tinha a responsabilidade de se adaptar às normas e condutas do técnico, compreendido como "o chefe inquestionável do programa esportivo" (p. 262). Assim, o atleta era incumbido de cumprir "cegamente" as diretrizes ditadas pelo técnico que, normalmente, considerava importantes apenas os aspectos físicos, técnicos e táticos da formação esportiva.

Com a mudança no paradigma do relacionamento técnico-atleta, os atletas começaram a questionar e a buscar respostas plausíveis para as atitudes e os comportamentos de seus mentores esportivos. $\mathrm{O}$ fato motivou importantes alteraçóes nos programas de treinamento e, fundamentalmente, na relação entre técnico-atleta. Parte dessas mudanças deve-se ainda ao novo conceito multidisciplinar adotado no âmbito do treinamento esportivo na segunda metade do século XX, principalmente, da psicologia do esporte, bem como a partir das contribuiçôes científicas advindas da sociologia e da antropologia. Essa nova realidade permitiu a releitura sobre a complexidade do fenômeno esportivo ${ }^{10}$.

Porém, apesar de mais de cinco décadas de estudos e movimentos para incorporar um modelo mais humanístico para a formação do atleta, o modelo autocrático de instrução esportiva continua presente na Ginástica Artística (GA), principalmente, na vertente competitiva ${ }^{11}$. Segundo LYLE ${ }^{2}$, esse modelo é caracterizado pelos seguintes aspectos:

primazia do técnico na tomada de decisóes; o relacionamento interpessoal possui uma abordagem diretiva e de dominação; a transmissão de conhecimentos, ensinamentos e aprendizados flui em uma única direção; o técnico determina as regras, as recompensas, os padróes e suas aplicaçôes; e, comportamento rígido e falta de empatia do técnico para com o atleta (p. 158).

Os estudos realizados por Bortoleto ${ }^{12} \mathrm{e}$ BAILleAU ${ }^{13}$ revelam que a estrutura social da GA de alto rendimento está apoiada em uma hierarquia de mandos na qual os técnicos possuem o poder da palavra e os ginastas se restringem ao cumprimento daquilo que foi determinado. Nesse sentido, CôtÉ et al. ${ }^{14}$ relatam que a intervenção "ditatorial" no processo de treinamento de GA ainda é vista por alguns treinadores como uma abordagem adequada para o trato com os ginastas.

Assim, é comum a percepção de que os técnicos de GA sejam considerados rígidos e ríspidos na sua forma de lidar com os seus atletas ${ }^{15}$, em alguns casos truculentos ${ }^{16}$, e que aplicam a pedagogia "de comando", segundo classificação de Mosston ${ }^{17}$.

A disciplina imposta ao processo de instrução esportiva dos atletas e que permeia a GA desde o seu nascimento está presente no controle do espaço, do tempo, dos corpos e das condutas durante o treinamento ${ }^{12}$. Parece que esse contexto disciplinador, à luz da teoria foucaultiana, estabelece um elo coercitivo entre a aptidão e a dominação e produz corpos submissos e exercitados, sob a escusa do êxito desportivo ${ }^{11,18}$. No entanto, embora a disciplina consista em um componente fundamental no processo de treinamento, Massimo e Massimo ${ }^{19}$ afirmam que os técnicos de GA enfrentam o desafio de "direcionar o espírito, não quebrá-lo" (p. 28), ou seja, buscam o equilíbrio na relação de poder que estabelecem com os ginastas.

Com intuito de compreender parte da dinâmica social-relacional construída entre os protagonistas do ginásio, o objetivo desse artigo é apresentar e discutir a relação técnico-atleta na Ginástica Artística Feminina (GAF) de alto rendimento com base em um estudo de caso do tipo etnográfico.

\section{O relacionamento técnico-atleta na ginástica artística}

Leonid Arkaev, um dos treinadores de GA mais importantes da história, defendia que devemos enfatizar, constantemente, a disciplina, a persistência, o "trabalho duro" e, também, os valores humanos no decorrer do processo de treinamento na modalidade. Ainda segundo o autor, é preciso estabelecer um relacionamento de dedicação e de lealdade mútua, entre técnico-atleta, o qual deve ser preservado para que o sucesso esportivo seja possível ${ }^{20}$.

Nas palavras do renomado ginasta espanhol Jesus Carballo JR. ${ }^{21}$, "a cada dia o técnico e o ginasta desenvolvem forte relacionamento como amigos e trabalham juntos como uma equipe; nas competiçóes eles ajudam e apoiam um ao outro para que tudo ocorra como planejado". Desse modo, 
tanto na perspectiva dos treinadores como dos pesquisadores, a qualidade desse relacionamento tem sido considerada um dos aspectos mais importantes para o êxito nessa modalidade ${ }^{19}$.

A qualidade dessa relação não é apenas determinada pelos conhecimentos do técnico e de como ele os transmite para os atletas, mas, sobretudo, pela sua competência em se conectar emocionalmente com os atletas e não os visualizar como simples corpos performáticos ${ }^{22}$. Em corroboração à essa perspectiva, a ex-ginasta estadunidense Amanda Borden elencou como um fator importante na sua carreira a percepção de que a técnica era a sua melhor amiga e que se importava com ela como pessoa e, em segundo plano, como atleta ${ }^{23}$.

$\mathrm{Na}$ opiniāo de $\mathrm{WEIss}^{24}$ a intensidade dessa interação na GA revela-se, até mesmo, nas formas de tratamento que, na modalidade, os técnicos são chamados pelo primeiro nome ou apelidos, enquanto na maioria dos outros esportes o mentor esportivo é denominado "o treinador" e/ou "o professor". Podemos exemplificar, por meio das palavras da ex-ginasta espanhola Elena Gomez, essa intensidade na relação técnico-atleta, além do uso de apelido: "Para mí, Fillo [Jesús Carballo - técnico] es como mi segundo padre" 25 .

Em geral, os relacionamentos de sucesso no esporte são caracterizados pela confiança, comprometimento, respeito e compreensão ${ }^{26}$. Essa dimensão afetiva e relacional proporciona aos atletas o sentimento de conforto, orientação, segurança e apoio nos diferentes momentos e estágios do seu desenvolvimento ${ }^{27}$.

A natureza da GA, ou seja, a alta exigência de capacidades físicas e a busca incessante pela eficiência e "perfeição" técnica, revelam a necessidade de envolvimento afetivo entre técnico-atleta. Os treinamentos intensos de força e de flexibilidade, a segurança na execução dos exercícios acrobáticos e o longo e insistente processo de ensino dos elementos, requerem o contato constante e, muitas vezes, físico (corporal), entre técnicos e atletas. Talvez, seja por essa razão que para muitos técnicos os/as ginastas de sua equipe são "SEUS"/"SUAS" ginastas e, portanto, são protegidos, guardados e cuidados como seu maior bem. Assim, trata-se de um relacionamento com características peculiares, que deve ser analisado sob a ótica também particular, com destaque na intensa confiança, entre as partes. Aliás, somente por meio dessa confiança é que os ginastas "arriscam" sua integridade física e depositam sua "sorte" nas mãos do técnico, conforme podemos observar no discurso de um dos símbolos da GAF, a ginasta romena NADia CoMANECI ${ }^{28}$ : "eu confiava à Bela [seu técnico] a minha vida no ginásio. Literalmente, ele impediu que eu quebrasse o meu pescoço. E, eu confiei nele a minha carreira, também” (p. 53).

Os próprios atletas são conscientes da importância de um bom relacionamento com o técnico. Eles sabem que a qualidade dessa relação contribuirá para o sucesso no esporte de alto rendimento, principalmente, devido à necessidade de convivência prolongada. Esse aspecto fica explícito no discurso da ex-ginasta Amanda Borden: "Mary Lee [Tracy] fez muitas coisas certas. Para ser bem-sucedido você tem que trabalhar juntos. Nosso relacionamento foi a chave para o nosso sucesso"29 (p. 125).

$\mathrm{Na}$ opinião de WeIss ${ }^{24}$, o técnico e o ginasta estabelecem um relacionamento de interdependência, um pacto tácito no qual se assume que o atleta depende do técnico e a reputação/carreira do técnico, por sua vez, depende da atuação do ginasta. RoberTs e Hemphill ${ }^{30}$ atentam para o fato de que há uma ironia nessa dependência, pois os atletas de alto rendimento, que deveriam ser os mais independentes são, na realidade, os mais dependentes. Essa contradição também foi observada por BORTOLETO ${ }^{18}$ ao pesquisar ginastas da seleção espanhola de GAM.

De fato, SANDS $^{31}$ relata que alguns técnicos percebem a "independência" dos atletas, ou seja, sua autonomia, como uma "doença" que precisa ser tratada e substituída pelo senso de dependência. $\mathrm{O}$ autor cita o exemplo de um técnico de futebol americano que compara os atletas aos soldados: "soldados perfeitos não eram pensadores independentes. Eles eram seguidores. Você joga da maneira que nós lhe ensinamos e você vence. É tão simples assim" (p.187). Salvaguardando-se as diferenças, no caso da GA, o ginasta deve confiar nos conhecimentos e na capacidade de prospecçâo e projeção do treinador e acatar suas decisóes.

Essa forma de conceber a educaçáo do corpo e da moral dos atletas, que acabamos de relatar, é semelhante e inspirada naquela utilizada para o ensino de ginástica entre o século XVIII e início do século XX, período que essa prática era utilizada para o treinamento militar ${ }^{32}$. Parece que esse modelo pedagógico deixou marcas profundas na concepção de formação dos ginastas e com resquícios que penduram até nossos dias ${ }^{16,18}$.

Dessa forma, observamos que o modelo tradicional de relacionamento entre o técnico coercivo e o atleta silencioso e obediente, citados por BurKe ${ }^{33}$, vem se mantendo hegemônico na GA, embora atenuados 
devido à maior atenção da sociedade contemporânea aos excessos. Por isso, os ginastas de alto rendimento tendem a se mostrar extremamente obedientes e disciplinados e se esforçam, constantemente, para obter a aprovação dos técnicos ${ }^{34}$.

WeIss $^{24}$ explica que "os pequenos ginastas aprendem seus elementos no ginásio, um enclave com normas culturais específicas e geralmente silenciosas" (p. 193), não ditas, que influenciam os valores, os princípios, as crenças e as condutas dos esportistas.

Ao analisar a estrutura social de um ginásio de GA de alto rendimento, Bortoleto ${ }^{18}$ concluiu que ela está apoiada em uma hierarquia na qual todos sabem exatamente o papel que devem desempenhar, bem como os seus poderes, deveres e responsabilidades. Nesse contexto, o autor cita que os técnicos possuem o poder da palavra e os ginastas se restringem a obedecer, fruto de uma tradiçáo e uma cultura hierárquica de comando. Logo, a manutenção dessa estrutura converte-se em objetivo primário entre os treinadores e demais membros do corpo técnico ${ }^{12}$. No referido estudo, é possível observar que até mesmo as instituiçóes responsáveis pelo processo (federaçóes, centros de treinamento, por exemplo) contribuem para a manutenção desse modelo.

Por conseguinte, como afirma DuQuin ${ }^{35}$, os atletas são treinados para se submeter aos comandos e sem questionamentos. Para que isso aconteça, conforme explica CARroN ${ }^{36}$, estabelece-se acordo subliminar entre técnicos e atletas sobre o papel de ambos no seu relacionamento, no qual os técnicos possuem o controle e os atletas são controlados.

Nunomura et al. ${ }^{37}$ consideram que as demandas da GA e o seu caráter disciplinador influenciam, em grande medida, o estereótipo dos atletas competitivos da modalidade. Assim, valores como a disciplina, a capacidade de repetir e de obedecer às ordens constituem, na opiniáo de Bortoleto ${ }^{18}$ (p. 440), "a coluna vertebral do caráter das pessoas que optam por esse esporte" e estáo presentes desde os primórdios da modalidade. Talvez, essa seja a maior dificuldade na atualidade, ou seja, a de encontrar, selecionar e treinar ginastas com esse perfil. No documentário Gimnastele ${ }^{38}$, o ex-técnico da equipe de GAF da Romênia Nicolae Forminte e o coreógrafo Valer Puia discutem questóes relativas às novas geraçóes de ginastas. Ambos concordam que na atualidade mudanças foram essenciais para atrair e manter novas atletas. $\mathrm{Na}$ análise deles, concessōes foram necessárias e certos aspectos na conduta profissional, especialmente, a imposição que caracterizou o trabalho no passado, não são mais aceitos com facilidade.

Percebemos, também, que muitos técnicos carregam consigo valores e crenças adquiridos durante sua carreira pregressa como ginastas. Tratamse de aspectos que são transferidos e reproduzidos na sua atuação como treinador ${ }^{39}$, o que contribui com a manutençáo dessa cultura de treinamento ${ }^{13}$.

Nessa relação, o técnico desempenha papel complexo, o que requer a compreensão e o comprometimento acerca de suas responsabilidades ${ }^{40}$. Alguns técnicos atuam de forma autocrática e, segundo LyLE$^{2}$, eles justificam essa forma de intervenção devido à necessidade de manter determinada rotina, ritmo e sem mudanças que possam interferir na dinâmica de funcionamento do ambiente esportivo. ToMLINSON e YoRGANCI ${ }^{41}$ citam $^{2}$ que esse estilo de instruçấo esportiva é fundamentado no desequilíbrio existente na divisão do poder presente nessa relação.

De acordo com STIRLING e KerR ${ }^{42}$, a assimetria da distribuição do poder ocorre devido à idade, ao gênero (quando o técnico masculino atua com a categoria feminina, por exemplo), ao grau de conhecimento, ao acesso aos recursos, à autoridade da posiçãa, ao poder de decisão e aos sucessos anteriores que favorecem o técnico.

Nesse sistema, o técnico é visto como detentor dos saberes necessários para o sucesso, enquanto o atleta necessita da orientação e do direcionamento desse mentor e, por essa razáo, se subordina ao comando do mesmo. Apesar disso, técnico e atleta estão inseridos em uma relaçáo de poder peculiar, na qual o esportista pode decidir se aceita ou não as instruçóes e imposições do técnico. Assim sendo, as atitudes do atleta podem influenciar e, até mesmo, alterar a forma de agir do treinador ${ }^{43}$. Contudo, muitos não são conscientes desse aspecto e, raramente, agem nesse sentido, e se rendem à tradição secular da GA.

De fato, se considerarmos que as ginastas iniciam seus treinamentos desde tenra idade e passam longos períodos sob o comando e a influência de um mesmo técnico, as açôes unilaterais e autocráticas dos mentores esportivos se tornam propícias, comuns e aceitas nesses espaços. SCHIAVON ${ }^{44}$ atenta para o fato de que as ginastas permanecem mais tempo com os técnicos do que com a família, fato que aumenta a influência deles sobre as atletas, muitas ainda crianças, deixando-as vulneráveis, até mesmo, aos seus exageros.

Ao longo da história da GA, alguns casos que exemplificam esses exageros foram denunciados, 
na sua maioria, posteriormente ao final da carreira esportiva das ginastas ${ }^{45-48}$. No contexto brasileiro poderíamos citar o documentário "Histórias do
Esporte: sem limites" ${ }^{39}$ que narrou uma série de fatos que relatam negligência no trato de lesôes, restrição de água, coerção, entre outras questôes.

\section{Método}

$\mathrm{Na}$ presente pesquisa, optamos pelo estudo de caso do tipo etnográfico ${ }^{50}$ por meio do qual visamos desvelar e compreender parte do universo social de um ginásio de treinamento de alto rendimento de GAF, mais especificamente, sobre a relação técnico-atleta.

Essa abordagem investigativa utiliza técnicas tradicionalmente atribuídas à pesquisa etnográfica (observação, entrevista, análise documental), mas sem perder a característica de um estudo de caso. Por isso, ANDRÉ ${ }^{50}$ sinaliza que nem todo estudo de caso é etnografia e, tampouco, toda etnografia é um estudo de caso.

A pesquisa de campo incluiu 16 visitas, com total de aproximadamente 85 horas de observação, registradas em um Diário de Campo (DC). Seguindo a metodologia de registro estabelecida por MARTUCCI ${ }^{51}$, durante cada sessão de observação redigimos notas de campo em versão preliminar que, posteriormente, foram retomadas para uma redação final. As notas foram constituídas por descrições das situaçôes vivenciadas e abrangeram aspectos relacionados ao local, aos sujeitos, aos diálogos, bem como a outras ações e acontecimentos ligados aos objetivos da pesquisa. Destacamos que comentários do próprio pesquisador entremearam o

\section{Resultados}

\section{Idiossincrasias do relacionamento técnico- -ginasta na microcultura do ginásio}

"O aquecimento começou com sete meninas. Ao som da contagem as ginastas das categorias préinfantil e infantil executaram o aquecimento no ritmo estabelecido pela técnica Luiza. Cada exercício possui um padráo que deve ser respeitado. $A$ atenção com a postura vai desde a cabeça até as pontas dos pés. O mesmo cuidado observado no aquecimento ocorreu durante todo o alongamento. As meninas são corrigidas e a técnica solicita-lhes responsabilidade. Em determinado momento diz que 'não é brincadeira' ao corrigir o grupo durante o relato descritivo com o fim de registrar as primeiras incursóes interpretativas dos fatos observados em busca de uma análise reflexiva. Primamos, no momento de análise, pela categorização e classificação dos dados, por meio da identificação da existência de padróes de relacionamento entre os mesmos.

O ginásio estudado, onde treinam diariamente ginastas de nível nacional e internacional, possuía equipes de GAF em todas as categorias competitivas, as quais: pré-infantil ( $\mathrm{n}=1)$, infantil $(\mathrm{n}=9)$, juvenil $(\mathrm{n}=3)$ e adulta $(n=6)$. O N ficou restrito às ginastas e turmas participantes nos Campeonatos Estaduais, Brasileiros e eventos internacionais no período 20092012. Compete citar que no ginásio havia um corpo técnico constituído por três técnicos dedicados ao alto rendimento na categoria feminina, todos com experiência nacional e/ou internacional.

Os participantes envolvidos na pesquisa foram identificados por meio de pseudônimos a fim de preservar a sua identidade real e evitar eventuais constrangimentos ou implicaçôes acerca dos assuntos abordados na pesquisa. Ressaltamos que o presente estudo foi aprovado pelo Comitê de Ética em Pesquisa da Escola de Educação Física e Esporte da Universidade de São Paulo (Parecer n. 225.814).

Assim como foi descrito no registro do DC, Bortoleto $^{18}$ menciona que no ginásio de GA impera o silêncio e a comunicação sutil mediada por movimentos afirmativos ou negativos com a cabeça que, em geral, não contradizem o técnico de forma explícita. Dessa forma, a "obediência, cega e sempre,

é o que se espera de todos aqueles que querem vencer.

aquecimento. Em vários momentos, Luiza questiona as atletas, mas sem ouvir uma resposta: 'Por que você não estende o joelho?' [...] 'Você não está ouvindo o que eu estou falando?’ [...] “O que você está fazendo?' Essas foram algumas das perguntas que as ginastas não se atreveram a responder naquela sessáo de treinamento" (DC 05/05/2012). 
Isso faz com que a ginástica olímpica [artística] se caracterize por excessos e autoritarismo por parte de atletas e treinadores envolvidos na modalidade" 52 (p. 153).

RYAN $^{45}$ cita que as ginastas são habituadas a agir sem questionar, pois os técnicos requerem completa subserviência. Enquanto os técnicos levantam a voz ou fazem comentários ríspidos, elas apenas se restringem a ouvir e a obedecer. E, foi precisamente isso que observamos nessa ocasião.

Na opinião de $\operatorname{CoAKLEY}^{53}$ (p. 490), essa relaçáo pode ser problemática, pois "é geralmente aceito que os técnicos possam humilhar, envergonhar e derrogar os atletas na tentativa de incentivá-los ao sucesso". $\mathrm{O}$ autor afirma que se espera que os atletas respondam a essa postura do técnico com firmeza e vontade para ultrapassar as adversidades do treinamento a fim de obter o sucesso nas competiçóes.

A busca pelo "endurecimento do caráter" das ginastas e de sua completa submissão é evidenciada em momentos nos quais as ginastas são repreendidas e questionadas pela autoridade do ginásio, ou seja, pelo técnico. Desse modo, o técnico não tem expectativa de resposta verbal, mas de ação física e de comportamento de superação por parte da atleta:

"Enquanto as ginastas da categoria adulta realizam o seu aquecimento, as meninas menores fazem $o$ preparo inicial e são acompanhadas pelo olhar da técnica que auxilia em alguns exercícios. As pequenas, também, se ajudam no preparo e a técnica Luiza sempre enfatiza a postura e a forma de execução correta. [...] Após alguns exercícios e correçóes a técnica repreende uma das ginastas ao questionar: "Você não tem preocupaçâo nenhuma em fazer certo?" Com esse questionamento, a técnica tenta conscientizar a ginasta que é importante realizar os exercicios de forma correta e atenta aos detalhes. Ela acrescenta que a ginasta 'morrerá na série devido à baixa resistência de força. [...] Após ser repreendida a ginasta inicia novamente os exercícios de forma correta sem esboçar nenhuma reação à fala da técnica ou justificar a sua falta de postura" (DC 16/06/2012).

As atletas têm pouco espaço para manifestar suas opiniōes e decisões pessoais e, dessa forma, são moldadas segundo as expectativas e os critérios de seus técnicos ${ }^{45}$. Quando trazemos à memória os Jogos Olímpicos de Atlanta, em 1996, recordamos a prova de salto da ginasta Kerri Strug quando, após torcer o tornozelo no primeiro salto, ela executa o segundo salto lesionada para contribuir com a conquista da medalha de ouro dos Estados Unidos.
Segundo STRUg e Lopez ${ }^{48}$, a queda no primeiro salto foi influenciada por uma série de fatores, dentre os quais: a ausência de feedback de seus técnicos pessoais sobre qual salto ela deveria realizar no aquecimento. "Normalmente Bela ou Martha diria a Dominique ou a mim exatamente o que fazer no aquecimento e em qual ordem. Mas, por alguma razão, ninguém [eu ou Dominique] sabia. Eu fiquei olhando para o Bela, gritando: o que eu devo fazer?”48 (p. 165).

Observamos que, apesar de se tratar de uma ginasta experiente, sua ação no interior do ginásio dependia fortemente de direcionamentos dos treinadores, cujo comportamento foi debatido por Bortoleto $^{18}$ quando estudou atletas de GAM de nível competitivo similar. A grande dependência das ginastas, com relação aos técnicos, explica-se pelo fato delas terem sido condicionadas, desde o primeiro momento, a atenderem os direcionamentos, comandos e ordens durante os treinamentos. Ao longo de todo o processo, que se prolonga por anos, raramente é permitido que as atletas tomem iniciativa, que decidam, que se posicionem. E quando isso acontece, sempre sob o prévio aval dos técnicos.

"Assim como em outros treinos, as jovens ginastas ficam à mercê do tempo após terminarem os exercicios [...]. Embora a rotina prevaleça, elas sempre aguardam as instruçóes dos treinadores, ainda que saibam o que viria na sequência. Em alguns momentos, elas são repreendidas por estarem ociosas. Por que você está parada? Terminou tudo? Então... não perde tempo, diz a técnica” (DC 14/04/2012).

A vigilância constante permeia toda a disciplina do treinamento, do início ao fim. E, como expóe FouCAULT ${ }^{54}$, "o poder na vigilância hierarquizada das disciplinas não se detém como uma coisa, não se transfere como uma propriedade; funciona como uma máquina” (p. 148). Na concepção desse autor, a vigilância se organiza de forma piramidal e produz o poder no qual os indivíduos são distribuídos e subjugados ao comando. As análises de BarkerRuchti e TinNING ${ }^{11}$ mostram que a GAF assimilou, perfeitamente, os pressupostos acima descritos, fazendo-os hegemônicos até a atualidade.

Os olhares dos mentores esportivos estão em todos os lugares do ginásio e acompanham o grupo de ginastas que, muitas vezes, estão distribuídas em atividades e aparelhos distintos. $\mathrm{Na}$ opinião de Foucault ${ }^{54}$, os olhares são calculados no poder disciplinador, o que o torna indiscreto e onipresente, pois, conforme o autor, "não deixa nenhuma parte 
às escuras e controla continuamente os mesmos que estão encarregados de controlar” (p.148).

"em alguns momentos as ginastas são surpreendidas com as correçóes dos técnicos que, muitas vezes, estão afastados ou cuidando de outros afazeres no ginásio. Isso demonstra que, mesmo distantes, eles estão supervisionando-as nas tarefas delegadas. Após executarem alguns exercícios o técnico pergunta: ' $O$ que falta?'. Ele não está satisfeito com o ritmo das ginastas da categoria adulta que estão no preparo e pede mais ritmo" (DC 03/03/2012).

Segundo CoAKLeY ${ }^{53}$, o corpo do atleta é treinado, controlado e monitorado de forma constante com o intuito de direcionar a sua vontade para que ele seja capaz de responder aos desafios e demandas do esporte de forma eficiente e vigorosa. Muitas vezes, a falha na execução de determinado elemento ou na realização de uma série é atribuída à falta de disciplina e de empenho da atleta.

"Ao executar a série [...], a ginasta tem problemas em todas as aterrissagens e queda [...]. O técnico oferece várias instruçóes e correçôes e diz que faltou vontade e que isso era reflexo dos treinos que a ginasta não havia se empenhado" (DC 12/05/2012).

"Após o treino que teve momentos de tensão e conflito, principalmente, durante a avaliação das séries, o técnico e a ginasta 'dialogam'. A ginasta fica com semblante aborrecido durante a fala do técnico e apenas escuta. Após alguns minutos eles se abraçam e se preparam para ir embora" (DC 12/05/2012).

Massimo e Massimo ${ }^{19}$ afirmam que o fato de sermos todos humanos torna natural que no relacionamento técnico-atleta a interação fique fragilizada e gere tensóes de tempos em tempos. Isso acontece, principalmente, quando a ginasta não atende às expectativas do técnico e esse acredita que seja pela falta de disciplina e/ou de vontade:

"O técnico que estava tenso, desde a arrumação dos colchóes nas barras, fica irritado ao ver a saida da atleta. Ele não se conforma com o erro. A ginasta parece apática. Ela volta a executar a saida e novamente erra. Ela aparenta estar sem motivação, aborrecida. A ginasta passa a série com erro e no Jager volta a refugar como no aquecimento. $O$ técnico se irrita e grita. Ele chuta um colchão extravasando a sua frustração e diz: 'sabia que ia acontecer isso com o Jager! Essa semana foi uma palhaçada! Por que você fica inventando essas coisas? Vai querer tirar isso (da série)? Tira tudo! Vai tirando!'. Ele se afasta da atleta e senta em uma das traves [...]. Ele não aparenta apenas impaciência, ele está frustrado com a situação. Sentado na trave ele observa a atleta que prepara as barras e as mãos para uma nova tentativa. A ginasta volta a executar a série e tem sucesso nos elementos de largada e retomada, mas cai na saida. Ele leva as mãos na cabeça, como se não acreditasse no que estava vendo. [...] A frustraçáo dele aumenta ao ver que a ginasta havia passado com sucesso pelos elementos da série com exceção de apenas um: a saida" (DC 12/05/2012).

STIRLING e KerR ${ }^{55}$ citam que o controle e o domínio que o técnico exerce sobre o atleta propicia o ambiente para comportamentos como esse supracitado, principalmente, devido à falta de liberdade do atleta para questionar as atitudes dos técnicos. No seu estudo com nadadores, os autores citam que açôes negativas dos técnicos contemplam comportamentos físicos (arremessar objetos, golpear paredes), verbais (insultos, comentários degradantes) e negação de apoio/atenção, algo também observado em muitos ginásios de GA.

"Após outro erro na saida, o técnico aparenta ter perdido a paciência com a ginasta, além de estar bravo e frustrado. Ela executa a série, mas cai na saída. Ele leva as mãos na cabeça como se não acreditasse no que estava vendo. Ele grita, anda como um leão em uma jaula irritado. Briga com a atleta e de forma irritada mostra como quer que ela reaja se cair faltando altura na saida. Nesse momento ele age de forma enérgica segurando a atleta pelo quadril elevando a no ar e fazendo-a aterrissar, como se ela fosse um boneco, fazendo-a repetir o momento de contado com o solo enquanto a segura pela cintura. A ginasta volta a realizar a saida e após repetir por duas vezes, com queda, consegue acertar uma vez. Essas últimas quedas ocorreram devido à diferentes erros, excesso de rotação e falta de rotação, o que demonstra que a atleta buscava resolver o problema e estava atenta aos conselhos do técnico" (DC 12/05/2012).

STIRLING e KerR ${ }^{55}$ citam que o receio, e até mesmo a admiração, que os atletas possuem dos técnicos, os incapacitam a questionar esse tipo de comportamento. E, os aspectos implícitos e aceitos na microcultura do ginásio e que são assimilados desde tenra idade, torna esse tipo de comportamento adequado, pois é visto como "correto" para se atingir o objetivo principal que seria o pódio na competição. Kerr e S TirLing ${ }^{56}$ afirmam que devido à forte tradição e ao tempo prolongado de convívio com os técnicos, os atletas consideram isso parte 
do processo que visa produzir um desempenho atlético de sucesso. Inclusive, parece que esse fato está fortemente relacionado ao recebimento de feedback, ou seja, respostas que reforçam o modelo exposto.

Massimo e Massimo ${ }^{19}$ afirmam que o ato de oferecer e receber feedback pode contribuir ou destruir o ambiente de treino, caso não seja ministrado da maneira correta e, consequentemente, incide no relacionamento técnico-atleta. No caso do evento ocorrido no treino de barras assimétricas, trecho extraído do DC citado anteriormente, o treino perdeu a harmonia e a atleta, ao invés de melhorar, só piorou. Parece-nos que além do medo que a dominava durante a execuçáo dos elementos e a dificuldade técnica na aterrissagem, ela temia pela reação do técnico que, por sua vez, ficava cada vez mais frustrado e tempestuoso. Essa dificuldade de comunicação entre eles evidencia outro problema também observado por BORTOLETO ${ }^{18}$, que consiste na falta de competências humanas/ relacionais e na supervalorização das competências técnicas. Em outras palavras, é comumente aceito que o técnico bom seja aquele que possui vasta experiência na modalidade e boa leitura sobre os aspectos técnicos da GA, mesmo que seja "inábil" no relacionamento e na comunicação com os atletas.

Percebemos que emoçóes e sentimentos diferentes permeiam as sessóes de treinamento e o relacionamento técnico-atleta. Muitas vezes, a alegria devido ao êxito na execução de um elemento com maestria é suplantada pelo temor na execuçâo de um elemento que envolve maior risco e complexidade, somadas à pressão do técnico. Conforme ARKAEV ${ }^{20}$, o trato com emoçóes positivas e negativas precisa ser balanceado pelo técnico na sua instruçáo esportiva. Assim, a pressão pela perfeição requer o contraponto que, quando não está presente, pode ter consequências nefastas, como as descritas nos documentários: Sueños Olimpicos $^{57}$, The Secret of Deva ${ }^{58}$ e Whatever it takes: pursuing the perfect $10^{59}$. Na GAF destacamos o medo como a emoçáo que necessita de mais atenção devido à sua maior emergência nos treinos, exemplificada no fragmento abaixo:

"outra ginasta vai para a trave onde deve executar os elementos acrobáticos da série. O técnico passa algumas instruçóes e se afasta para corrigir outra atleta. Enquanto isso, a ginasta arruma os colchóes. $A$ atleta demora para arrumar o aparelho $e$ iniciar os exercícios. [...] após certo tempo, ela continua na trave e demonstra medo em executar o mortal. Ela refuga e demora entre os exercícios. Consequentemente, o técnico se irrita com a demora e a atitude da atleta. Ele faz pressão para que ela termine a tarefa elevando a sua voz e em tom irônico" (DC 05/05/2012).

Kerr e Stirling ${ }^{56}$ atentam que, apesar da influência positiva dos técnicos no desenvolvimento de atletas, esses podem recorrer às formas negativas de comunicação e, também, de táticas questionáveis para alcançar o sucesso. Ainda de acordo com os autores, muitos técnicos cometem o abuso mental e verbal na sua prática.

$\mathrm{Na}$ percepção de Palframan ${ }^{60}$, gritos ou comentários depreciativos são utilizados com vista a "endurecer/melhorar" o aspecto psicológico dos atletas, incitando-os a cumprir tarefas por medo, sob pressão. Essa estratégia também foi evidenciada nos documentários Sueños Olimpicos ${ }^{57}$, The Secret of Deva ${ }^{58}$ e Whatever it takes: pursuing the perfect $10^{59}$, os quais mostram que não se trata de um modus operandi isolado, mas comum em muitos ginásios de GA. Nesse sentido, Kerri Strug ${ }^{61}$ fez o seguinte relato sobre o seu antigo técnico: "ele sabia como conseguir o máximo de cada criança. Eu penso que grande parte de sua estratégia de motivação era o medo. Quando eu errava, ficava mais preocupada com o que ele pensaria do que com o erro" (p. 2a).

Inclusive, o medo está relacionado aos castigos físicos, como citam Krane et al. ${ }^{62}$ por meio de relatos de uma ginasta: "se você cair da trave, cada vez que você cair, mesmo que você esteja aprendendo um elemento novo, você fará 10 flexões de braço". Esse fato foi perceptível em alguns momentos da pesquisa, principalmente, na realização de tarefas nos aparelhos e na execução de determinado número de séries.

"Se você continuar fazendo desse jeito vai repetir tudo!' [...] 'Todas vão ter que repetir, porque a Milena fez com as pernas dobradas e não marcou.' [...] 'Essa não contou, porque teve queda' (DC 22/09/2012; DC 12/05/2012).

Percebemos que o relacionamento técnicoatleta é influenciado, de forma pronunciada, pela concepção de que o sucesso na GA, com vista ao alto rendimento, só é logrado com comprometimento, dedicação e disciplina que, muitas vezes, envolvem sacrifícios e riscos. Embora essas características sejam debatidas na literatura, são os exageros e a falta de acompanhamento mais cuidadoso, como aquele realizado pelos psicólogos esportivos, que expóem as ginastas aos problemas que podem interferir ou mesmo interromper suas carreiras esportivas.

COAKLeY $^{53}$ relata que o poder e o desempenho esportivo encorajam os indivíduos desse contexto a estabelecer recordes, a buscar o limite humano e a usar o corpo como máquina. E, muitos assumem 
que o sucesso só será obtido com trabalho duro, o que poderia fugir do controle. Donnelly ${ }^{63}$ considera que muitos técnicos não têm intenção de agir de forma negativa e agressiva para prejudicar seus atletas. Mas, que o próprio contexto esportivo os direciona a tomar decisóes que poderiam contrapor ao bem-estar dos esportistas sob seu comando.

\section{Discussão}

Em contrapartida ao ideal do esporte de participação que, segundo Coackley, percebe o corpo como "jardins" que devem ser cultivados e cuidados para promover o crescimento pessoal, no esporte de competição e, no caso específico desse estudo, a GAF, continua a conceber e a utilizar os corpos das atletas como máquinas disciplinadas ${ }^{46}$.

Essa visão reducionista dos técnicos, que amortizam o senso crítico das ginastas à corpos que agem como dispositivos mecânicos que obedecem sem questionar até o limite, é implementada por meio de um processo de formação esportiva no qual as ginastas firmam um acordo subliminar. E, dessa forma, aceitam e cumprem com as regras inerentes à microcultura do ginásio. Ressaltamos que na GAF, e na GA de um modo geral, os corpos sáo inseridos nessa cultura de treinamento desde tenra idade, a qual direciona os padróes de comportamento desde os primeiros saltos na modalidade mediados, principalmente, por meio do relacionamento técnico-atleta.

A análise da relação construída entre técnicos e ginastas, revela que ao mesmo tempo em que ela é tão próxima, devido ao contato físico constante nas ajudas manuais e às longas horas de treinamento num espaço reduzido, ela é paradoxalmente distante devido à hierarquia de poder que rege a dinâmica social do ginásio. Assim, urge a necessidade de modificar esse padráo de interação, tornando a comunicação mais efetiva entre esses protagonistas do ginásio e a relação mais equilibrada, conforme os padrōes desejados na atualidade.

Corroboramos a opinião de $\mathrm{LAVOI}^{64}$ que considera a comunicação como um veículo que permite desenvolver a relação técnico-atleta, pois é possível transmitir, além da expertise esportiva, o senso de cuidado, preocupação, respeito e confiança. Ademais, a constituição, o aprimoramento, a manutenção e, até mesmo, a dissolução dessa relação ocorre por meio de processos de comunicação. E, o diálogo emerge como um meio importante para o sucesso desse relacionamento e do êxito esportivo ${ }^{29}$.

A conjuntura dessa relação determina que as instruçôes dos técnicos precisam ser aceitas com confiança e que as ginastas acreditem fielmente na competência de prospecção dos técnicos e, em muitas situações, depositem a sua integridade física nas mãos de seus mentores esportivos. Contudo, essa relação deve ser desenvolvida por meio da conscientização das atletas acerca das necessidades e dos cuidados imbricados nas diferentes situaçôes vividas no cotidiano do ginásio, num ambiente menos impositivo, e contrário à pedagogia do medo, conforme debatemos no decorrer do estudo.

Sabemos que alguns técnicos recorrem à autocracia como forma de doutrinar as ginastas e promover, unilateralmente, seu modo de trabalho, produzindo assim uma relação de dependência. Entretanto, esse tipo de formação esportiva pode incidir na saúde física e psicológica das atletas. E, consequentemente, restringir as oportunidades de sucesso. Parece-nos que a qualidade do relacionamento técnico-atleta poderia potencializar o estresse ou, pelo contrário, auxiliar a diminuí-lo e, consequentemente, combater o burnout e o dropout.

Ressaltamos, assim como Krane et al. ${ }^{62}$, que para cada ginasta que obtém sucesso na modalidade, muitas atletas não o lograrão. Mas, as consequências impostas durante o treinamento poderão impactar nas demais fases de vida de todas as atletas.

Dessa forma, concordamos com Massimo e MAssimo ${ }^{19}$ quando afirmam que uma das chaves para o sucesso no processo de ensino-aprendizagem, bem como no treinamento de alto rendimento de GA, está no diálogo e na construção de um relacionamento equilibrado entre técnicos e ginastas. Entretanto, percebemos que, muitas vezes, essa não é a realidade vivida no interior dos ginásios, pois muitos técnicos temem a perda de liderança e o poder que detém no relacionamento com os atletas. Por isso, ressaltamos a necessidade de que o técnico esteja disposto ao diálogo e incentive seus atletas a se comunicarem, a fim de identificar e solucionar problemas, e que essa relação seja mais aberta e transparente, inclusive com os familiares. Certamente, a qualidade dessa relação poderá otimizar os resultados esportivos e a formação holística das ginastas. 


\section{Abstract}

\section{The coach-athlete relationship in women's artistic gymnastics}

The quality of personal relationships, outlined in the Sport environment, is crucial to the experience in sport and influences the results achieved by its protagonists: coaches and athletes. The present paper discusses the coach-athlete relationship in Women's Artistic Gymnastics through a study case of ethnographic type. The research was developed in a high performance gym with world class gymnasts. We observed in this microculture that coaches and athletes are subordinated to the cultural idiosyncrasies mediated by values and principles that impact, substantially, on their behaviors which steer this unique relationship with attitudes that in an outside context would not be accepted and/or allowed. Gymnasts and coaches have a tacit agreement in which athletes are seen as performatic bodies that should follow the coaches' guidelines unquestioningly. Coercive acts, lack of dialogue, constant vigilance, surveillance and demands permeate this relationship scarcely discussed in specialized literature.

KEYWORDS: Gymnast; Training-Culture; Athlete Development.

\section{Referências}

1. Martens R. Successful coaching. $3^{a}$ ed. Champaign: Human Kinetics; 2004.

2. Lyle J. Sports coaching concepts: a framework for coaches' behavior. Nova York: Routledge; 2002.

3. Jowett $S$, Ntoumanis $\mathrm{N}$. The coach-athlete relationship questionnaire (CART-Q): development and initial validation. Scandinavian Journal of Medicine \& Science in Sports. 2004;14(4):245-57.

4. Bloom GA, Durand-Bush N, Schinke R, Salmela JH. The importance of mentoring in the development of coaches and athletes. International Journal of Sport Psychology. 1998;29(3):26781.

5. Philippe RA, Seiler R. Closeness, co-orientation and complementarity in coach-athlete relationships: what male swimmers say about their male coaches. Psychology of Sport and Exercise. 2006;7(2):159-71.

6. Poczwardowski A, Barott JE, Henschen KP. The athlete and coach: their relationship and its meaning, results of an interpretive study. International Journal of Sport Psychology. 2002;33(1):116-40.

7. Rhind DJA, Jowett S. Relationship maintenance strategies in the coach-athlete relationship: the development of the COMPASS model. Journal of Applied Sport Psychology. 2010;22(1):106121.

8. Scott J. Athletics for athletes. Oakland: Other Ways Press; 1969.

9. Lanning W. Coach and athlete personality interaction: a critical variable in athletic success. Journal of Sport Psychology. 1979;1(4):262-7.

10. Calhoun DW. Sport, culture, and personality. 2a ed. Champaign: Human Kinetics Publishers; 1981.

11. Barker-Ruchti N, Tinning R. Foucault in leotards: corporeal discipline in women's artistic gymnastics. Sociology of Sport Journal. 2010;27(3):229-50.

12. Bortoleto MAC. A ginástica artística masculina (GAM) de alto rendimento: observando a cultura de treinamento desde dentro. Revista Motricidade. 2007;3(1):323-36.

13. Bailleau L. La culture gimnique: une ethnographie d'un groupe de haut niveau [dissertação]. Orleans: Universidad de Orleans, Facultad de Deporte y Educación Física; 2001.

14. Côté J, Salmela JH, Russell S. The knowledge of high performance gymnastic coaches: competition and training considerations. The Sport Psychologist. 1995;9(1):76-95.

15. Nunomura M. Ginástica artística. São Paulo: Odysseus; 2008.

16. Barker-Ruchti N. Women’s artistic gymnastics: an (auto-)ethnographic journey. Basel: Gesowip; 2011.

17. Mosston M. Teaching physical education. 2a ed. Columbus: Merrill; 1981.

18. Bortoleto MAC. La lógica interna de la gimnasia artística masculina (GAM) y estúdio etnográfico de um gimnasio de alto rendimiento [tese]. Lleida: Universitat Lleida, INEFC Lleida; 2004. 
19. Massimo J, Massimo S. Gymnastics psychology: the ultimate guide for coaches, gymnasts and parents. Nova York: Morgan James Publishing; 2013.

20. Arkaev L. My coaching philosophy. In: Langsley E, editor. Gymnastics in perspective. Montier: FIG; 2000. p. 64-73.

21. Carballo Junior J. A family affair. In: Langsley E, editor. Gymnastics in perspective. Montier: FIG; 2000. p. $24-5$.

22. Cassidy T, Jones RL, Potrac P. Understanding sports coaching: the social, cultural and pedagogical foundations of coaching practice. London: Routledge; 2004.

23. Silby C, Smith S. Games girls play: understanding and guiding young female athletes. Nova York: St. Martin’s Press; 2000.

24. Weiss MS. Culture, context and content analysis: an exploration of elite women gymnasts in the high school world. In: Dyck N, editor. Games, sports and cultures. Oxford: Berg; 2000.

25. Agência de Notícias Internacionais Espanhola. "Estoy segura de que Jesús Carballo no hizo las barbaridades de las que le acusan” [Internet]. [local desconhecido]: 20 Minutos Editora; 2013 maio 22 [citado em 2018 mar 6]. Disponível em: $<$ https://goo.gl/NGhbnA>.

26. Jowett $S$. When the "honeymoon" is over: a case study of a coach-athlete dyad in crisis. Sport Psychologist. 2003;17(4):444-60.

27. Yang SX, Jowett S. Psychometric properties of the coach-athlete relationship questionnaire (CART-Q) in seven countries. Psychology of Sport and Exercise. 2012;13(1):36-43.

28. Comaneci N. Letters to a young gymnast. Nova York: Basic Books; 2004.

29. Cogan KD, Vidmar P. Gymnastics. Morgantown: Fitness Information Technology; 2000.

30. Roberts TJ, Hemphill DA. Banning drugs in sport: ethical inconsistencies. Submission to the senade standing committee on environment, recreation and the arts, Australia. [local desconhecido: editora desconhecida]; 1988.

31. Sands RR. Gut check! An anthropologist's wild ride into the heart of college football. Carpinteria: Rincon Hill Books; 1999.

32. Soares CL. Educaçáo física: raízes europeias e Brasil. Campinas: Autores Associados; 2004.

33. Burke M. Obeying until it hurts: coach-athlete relationships. Journal of the Philosophy of Sport. 2001;28(2):227-40.

34. Tofler IR, Stryer BK, Micheli LJ, Herman LR. Physical and emotional problems of elite female gymnasts. New England Journal of Medicine. 1996:335(4):281-3.

35. Duquin M. The body snatchers and Dr. Frankenstein revised: social construction of bodies and sport. Journal of Sport and Social Issues. 1994;18(3):268-81.

36. Carron AV. Role behavior and coach-athlete interaction. International Review of Sport Sociology. 1978;13(1):51-6.

37. Nunomura M, Oliveira MS, Roble OJ, Carbinatto M. Ginástica artística competitiva e a filosofia dos técnicos. Motriz. 2012;18(4):678-89.

38. Reporter special: gimnastele. Reportagem de Ioana Răduca. Bucareste: Antena 3. 2008.

39. Schenewark JD. Work-family conflict and enrichment: a study of college coaches [tese]. Austin: The University of Texas at Austin; 2008.

40. Sullivan PA, Wilson DJ. The coach's role. In: Cohen GL. Women in sport: issues and controversies. Newbury Park: Sage; 1993.

41. Tomlinson A, Yorganci I. Male coach/female athlete relations: gender and power relations in competitive sport. Journal of Sport and Social Issues. 1997;21(2):134-55.

42. Stirling AE, Kerr GA. Abused athletes' perceptions of the coach-athlete relationship. Sport in Society: Cultures, Commerce, Media, Politics. 2009;12(2):227-39.

43. Markula P, Pringle R. Foucault, sport and exercise: power, knowledge and transforming the self. Londres: Routledge; 2006.

44. Schiavon LM. Ginástica artística feminina e história oral: a formação desportiva de ginastas brasileiras participantes de jogos olímpicos (1980-2004) [tese]. Campinas: Universidade Estadual de Campinas, Faculdade de Educação Física; 2009.

45. Ryan J. Little girls in pretty boxes: the making and breaking of elite gymnasts and figure skaters. New York: Doubleday; 1995.

46. Sey, J. Chalked up: inside elite gymnastics' merciless coaching, overzealous parents, eating disorders, and elusive Olympic dreams. Nova York: HarperCollins; 2008.

47. Moceanu, D, Williams, P, Williams, T. Off balance: a memoir. Nova York: Touchstone; 2012.

48. Strug K, Lopez JP. Landing on my feet: a diary of dreams. Kansas: Andrews McMeel; 1998.

49. Histórias do esporte: sem limites. Reportagem de Ronaldo Kotscho. Direção de José Trajano. São Paulo: ESPN Brasil. 2008.

50. André EDA. Etnografia da prática escolar. Campinas: Papirus; 1995.

51. Martucci EM. Estudo de caso etnográfico. Revista de Biblioteconomia de Brasília. 2001;25(2):167-80.

52. Rubio K. O atleta e o mito do herói: o imaginário esportivo contemporâneo. São Paulo: Casa do Psicólogo; 2001.

53. Coakley J. Sport in society: issues \& controversies. 7a ed. New York: McGraw-Hill; 2001.

54. Foucault M. Vigiar e punir: nascimento da prisão. 29a ed. Petrópolis: Vozes; 2004.

55. Stirling AE, Kerr GA. Defining and categorizing emotional abuse in sport. European Journal of Sport Science. 2008;8(4):173-81. 
Oliveira MS, et al.

56. Kerr GA, Stirling AE. Parents' reflections on their child's experiences of emotionally abusive coaching practices. Journal of Applied Sport Psychology. 2012;24(2):191-206.

57. Sueños olimpicos (the red race). Direção de Chao Gan. Produção executiva de Qiming Ying. Shangai: Shanghai Double Montage Production Company. 2008.

58. The secret of deva. Direção de Anca Miruna Lazarescu. Produção de Adina Bouwer. Munique: Twinpix Filmproduktion. 2007.

59. Whatever it takes: pursuing the perfect 10. Reportagem de Carol Lin. Allentown: CNN. 2003.

60. Palframan, D. Expert deplores emotional abuse in sports. Coaches Report. 1994;1(2):3-5.

61. Raboin S. Bela is back on U.S. team. USA Today. 1999 nov: 1a-2a.

62. Krane V, Greenleaf CA, Snow J. Reaching for gold and the price of glory: a motivational case study of an elite gymnast. The Sport Psychologist. 1997;11(1):53-71.

63. Donnelly P. Child labour, sport labour: applying child labour laws to sport. International Review for the Sociology of Sport. 1997;32(4):389-406.

64. LaVoi NM. Interpersonal communication and conflict in the coach-athlete relationship. In: Jowett S, Lavallee D, organizadores. Social psychology in sport. Vol. 10. Champaign: Human Kinetics; 2007.

ENDEREÇO

Maurício Santos Oliveira

Núcleo de Pesquisa em Ginástica (NPG)

Centro de Educação Física e Desportos

Universidade Federal do Espírito Santo

Av. Fernando Ferrari, 514 - Goiabeiras 29075-810 - Vitória - ES - Brasil e-mail: mauricio_olliveira@yahoo.com.br
Recebido para publicação: 12/10/2014

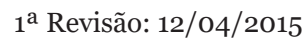

$2^{\text {a }}$ Revisão: 28/10/2015

Aceito: 09/03/2016 